\title{
Fortalecimento do Sistema do Mérito no Novo Plano de Classificação
}

\author{
Cláudio Aguiar \\ Diretor de Pessoal do \\ TRT da 6." Reglão; \\ advogado
}

\begin{abstract}
"Quando não conseguimos os resultados que desejamos, temos tendência para procurar a causa em toda parte, exceto onde geralmente se encontra na escolha de métodos de controle apropriados."
\end{abstract}

DOUGLAS MCGREGOR

S U MARIO : INTRODUÇÃO; PARA UM NOVO PLANO, UMA NOVA FILOSOFIA; FORTALECIMENTO DO SISTEMA DO MÉRITO : O CAMINHO CERTO; DETERMINANTES DOS FATORES DE EFICIENCIA.

\section{INTRODUÇÃO}

Não procuraremos esgotar as diversas variantes que se ligam às diretrizes fundamentais do Novo Plano de Classificação de Cargos do Serviço Civil da União, mas simplesmente indicar, nestas breves considerações, alguns elementos básicos que presidem 0 desencadeamento do processo de valorização do servidor públiCo, mediante o fortalecimento do sistema do mérito do Novo Pla. no de Classificação.

- Nonte o elenco de normas e princípios gerais que norteiam alguvo Plano de Classificação de Cargos, basta a enumeração de da forms deles para se ter uma idéia de sua profundidade. Partindo gos ormulação de planos de classificação e de retribuição de carempregos do Serviço Civil da União, sistemática implanta- 
ção do treinamento do pessoal, definição de critérios seletivos, até a elaboração de regulamentos relativos a provimentos, ascensẫo e progressão funcionais, chegaremos, enfim, à edificação de um verdadeiro e funcional sistema de administração de pessoal científicamente estruturado.

Esperamos, por outro lado, que a orientação política não interfira na técnica. Em geral, os planos básicos sofrem alterações nas áreas de execução, quando não se mudam totalmente os seus objetivos.

Fortes interferências da política sobre a técnica tivemos, por exemplo, com as diretrizes iniciais da Reforma Administrativa. Desde o final da Segunda Grande Guerra que o Governo brasileiro passou a se preocupar com os instrumentos utilizados pela administração pública.

Em 1951, o Presidente Vargas, motivado pela ineficiência da máquina administrativa brasileira, designara uma comissão interpartidária com a finalidade específica de analisar e investigar as condições para introdução de uma profunda reforma da Administração Pública. Concluídos os estudos preliminares, nada foi posto em prática, face a graves perturbações políticas que redundaram no suicídio do Presidente da República, em agosto de 1954.

Advindo a Administração Kubitschek, resurgiram duas comissões : a de Simplificação Burocrática e a de Estudos e Projetos Administrativos - ambas objetivando a melhoria do desempenho dos Serviços e das diversas unidades que integram o Serviço $\mathrm{Ci}$. vil da União. Dos estudos e projetos apresentados pelas duas comissões referidas, foram criados dois grandes Ministérios : o das Minas e Energia e o da Indústria e Comércio.

Em 1962, no decorrer da administração Goulart, o Governo deu mais um passo, exatamente porque se chegara à evidência de que era imperiosa a necessidade de se implantar uma profunda reforma administrativa, ao nomear um Ministro Extraordinário para cuidar do assunto, o qual ficou com a responsabilidade de elaborar, no prazo de um ano, com a colaboração de uma equipe de técnicos altamente qualificados, os projetos básicos. No fim de 1963 , estes projetos foram enviados ao Congresso Nacional para exame e conseqüente votação.

Meses depois, em abril de 1964, como conseqüência de uma crise política que implicou na deposição do então Presidente da República, novamente ficaram paralisados os estudos da Reforma Administrativa. 
Só em pleno regime revolucionário do Presidente Castello Branco, em 25 de fevereiro de 1967, através do Decreto-Lei n. ${ }^{\circ} 200$, foi aprovada a nova organização da administração federal, ficando definitivamente estabelecidas as diretrizes da Reforma Administrativa.

Com este rápido bosquejo dos antecedentes históricos da Reforma em causa, procuramos mostrar as diversas interferências da política sobre a técnica programada. Acreditamos, todavia, que ante as conseqüências eficazes que todos já começam a sentir, com a atual implantação gradativa dos diversos grupos que irấo constituir os instrumentos do Plano de Classificação de Cargos, está desencadeada uma verdadeira revolução no âmbito do Serviço Civil da União, que não poderá mais ser paralisada sob pena de comprometer a consecução dos mais elevados objetivos nacionais.

\section{PARA UM NOVO PLANO, UMA NOVA FILOSOFIA}

Com a promulgação do Decreto-Lei n. 200 , de 1967 , ficou o Governo Central com a responsabilidade de rever a legislação e as normas regulamentares relativas ao pessoal do Serviço Público Civil, objetivando ajustá-las aos seguintes princípios :

I - "valorização e dignificação da função pública e do servidor público;

II - Aumento da produtividade;

III - Profissionalização e aperfeiçoamento do servidor público; fortalecimento do sistema do mérito para ingresso na função pública, acesso à função superior e escolha do ocupante de funções de direção e assessoramento;

IV - Conduta funcional pautada em normas éticas, cuja infração incompatibilize o servidor para a função;

V - Constituição de quadros dirigentes, mediante a formação e aperfeiçoamento de administradores capacitados a garantir a qualidade, produtividade e continuidade da ação governamental, em consonância com critérios éticos especialmente estabelecidos;

VI - Retribuição baseada na classificação das funções a desempenhar, levando-se em conta o nível educacional exigido pelos deveres e responsabilidades do 
cargo, a experiência que o exercício deste requer, a satisfação dos outros requisitos que se reputarem essenciais ao seu desempenho $\mathrm{e}$ as condições do mercado de trabalho.

VII - Organização dos quadros funcionais, levando-se em conta os interesses de recrutamento nacional para certas funções e a necessidade de relacionar - mercado de trabalho local ou regional, o recrutamento, a seleção e a remuneração das demais funções.

VIII - Concessão de maior autonomia aos dirigentes e chefes da administração de pessoal, visando a fortalecer a autoridade de comando, em seus diferen. tes graus, e dar-lhes efetiva responsabilidade pela supervisão e rendimento dos serviços sob sua jurisdição;

IX - Fixação da quantidade de servidores, de acordo com as reais necessidades de funcionamento de cada órgão, efetivamente comprovadas e avaliadas na oportunidade da elaboração do orçamento-programa, e estreita observância dos quantitativos que forem considerados adequados pelo Poder Executivo no que se refere aos dispêndios de pessoal; aprovação das lotações, seguindo critérios objetivos que relacionem a quantidade de servidores, às atribuições e ao volume de trabalho do órgão;

X - Reabsorção do pessoal ocioso mediante aproveitamento do pessoal excedente ou aproveitamento dos desajustados em funções compatíveis com as suas comprovadas qualificações e aptidões vocacionais, impedindo-se novas admissões enquanto houver servidores para a função.

$\mathrm{XI}$ - Instituição, pelo Poder Executivo, de reconhecimento do mérito aos servidores com sugestões, planos e projetos não elaborados em decorrência do exer cício de suas funções e dos quais possam resultar aumento de produtividade e redução dos custos operacionais da administração;

XII - Estabelecimento de mecanismos adequados à apresentação por parte dos servidores nos vários níveis organizacionais, de suas reclamações e reinvidica. 
ções, bem como a rápida apreciação pelos órgãos administrativos competentes nos assuntos nelas contidos;

XIII - Estímulo do associativismo dos servidores para fins sociais e culturais" 1

Observa-se, portanto, da simples leitura dos princípios acima enumerados, que se procura dar uma nova dimensão ao servidor público.

Essa visão nova, por outro lado, só poderia levar o Governo a tomar medidas profundas, sobretudo no que se refere à implantação de novos critérios para a Administração de Pessoal Civil, objetivando um sistema cientificamente estruturado, capaz de desencadear o processo renovador. O velho DASP precisava sofrer uma mudança profunda. E efetivamente começou a mudar, conforme o que dispõe o Dec. $n .{ }^{\circ} 66.222$, de 17 de fevereiro de 1970 que estabeleceu os instrumentos indispensáveis à dinamização de um autêntico "feed-back" do sistema de pessoal do Serviço Público Civil da União.

No Plano da profissionalização e aperfeiçoamento do servidor público e do fortalecimento do sistema do Mérito, impunha-se uma mudança radical. Muitos afirmavam que seria uma posição romântica tentar mudar a sistemática de administração de pessoal que conhecíamos desde 0 advento da Lei $n .^{\circ} 3.780 / 60$, que estabeleceu um Plano de Classificação de Cargos de aplicação imediata, com princípios rígidos e inflexíveis.

Ao longo dos dez anos que se seguiram à implantação do Plano de Classificação preconizado pela Lei n. ${ }^{\circ} 3.780$, de 1960 , os técnicos não pararam um instante de criticar e de responsabilizar os administradores pela completa ineficiência dos serviços públicos. E, via de regra, a culpa recaía na impotência do Plano, que não era capaz de estabelecer maiores atrativos aos servidores e, por outro lado, não concorria com as ofertas da iniciativa privada. Nessa altura, quer nos parecer que o Plano de Classificação já não convinha como solução para os graves problemas que afetavam a Administração Pública. Assim, Gustave Le Bon tem razão quando afirmou que é
fácil reconhecer-se o dia preciso em que uma grande crença há de morrer: é aquele em que ela começa a ser discutida. ${ }^{2} \mathrm{E}$ o Plano de Classificação instituído pela Lei n. 3.780 , de 1960 , não só começava a ser discutido, mas era duramente criticado. Na verda. de, os seus dias estavam contados. 
Com a promulgação da Lei $n \cdot{ }^{\circ} 5.645$, de $11-12-70$, surgiu a grande esperança de todos os servidores públicos, que visualizavam a possibilidade institucional de ver prestigiada a profissionalização, o aperfeiçoamento e reforçado em todos os sentidos o sistema do mérito.

Não bastava, porém, a expedição de leis. O fundamental é a aplicação adequada destas Leis. O DASP, já reestruturado e renovado, passou à aplicação das diretrizes da Lei n. ${ }^{\circ} 5.645 / 70$.

As diretrizes traçadas pela Lei acima referida traziam no bojo uma nova filosofia. Tudo deverá ser adequado à realidade brasileira. Por isso, não se foi buscar métodos estrangeiros. A solução para o problema teve que se harmonizar com as nossas pecu. liaridades.

O Novo Plano é instituído em aberto e leva em conta, preponderantemente, a importância da atividade para o desenvolvimento nacional, a complexidade e responsabildade das atribuições exercidas e as qualificações requeridas para o desempenho das atribuições. Tais pontos afastam, de logo, qualquer possibilidade de fixação de critérios ou princípios apriorísticos, que, em regra, levam à improvisação.

Segundo as diretrizes do referido diploma legal, a implantação do Novo Plano será feita por órgão, atendida uma escala de prioridade, na qual se levará em conta a implantação prévia da Reforma Administrativa, com base no Decreto-Lei n. ${ }^{200}$, de 1967, o estudo quantitativo e qualitativo dos órgãos, tendo em vista a nova estrutura e atribuições decorrentes da implantação da Reforma Administrativa e, por fim, a existência de recursos orçamentários para fazer face às respectivas despesas.

\section{FORTALECIMENTO DO SISTEMA DO MÉRITO : O CAMINHO CERTO}

Como salientamos, um dos princípios básicos preconizados pela nova filosofia da moderna Administração Pública é o fortalecimento do sistema do Mérito para ingresso na função pública, acesso a função superior e escolha dos ocupantes de funçôes de direção e assessoramento.

A tais projeções se atrelam, ainda, o reconhecimento do mérito aos servidores que desejam realmente contribuir com sugestões, planos e projetos elaborados em decorrência do exercício de suas funções e das quais possam resultar aumento de pro. 
dutividade e redução dos custos operacionais de administração pública.

A adoção desses princípios é um imperativo do atual está. gio de desenvolvimento que alcançamos. O Estado Moderno não se preocupa apenas com as tradicionais operações que os nossos antepassados tanto defenderam. Ao lado dos serviços meramen. te de interesse comum, o Estado é obrigado a enfrentar situações singulares. E o que é mais interessante: a agir como se fosse uma empresa. Exemplo disso são as diversas atividades para as quais o Governo foi forçado a permitir o regime trabalhista ou contratual para os servidores, em decorrência da necessidade de tornar mais flexível a administração de pessoal.

\section{No mesmo sentido, afirma THEMISTOCLES BRANDÃO CA-
VALCANTI que :}

"O Estado vem absorvendo de tal forma as atividades individuais e particulares que foi obrigado a criar novas formas de administração, com menos rigidez e com outra estrutura mais de acordo com os interesses comerciais desses serviços, o que veio provocar uma multiplicidade de formas de organização e a instituição de departamentos muito assemelhados às empresas particulares". 3

O sistema do mérito adotado e fortalecido pelos nossos princípios da Reforma Administrativa, confirmados pelos desdobramentos das diretrizes instituídas pela Lei n. $5.645 / 70$, envolve, além do tradicional concurso público de provas e títulos, outros, como formação prévia e livre escolha. O sistema da formação prévia é o adotado, por exemplo, na investidura na carreira de Diplomata. O da livre escolha é mais abrangente, porquanto se aplica a todos os ocupantes dos cargos que, por sua natureza, devam ser providos pelo critério da confiança.

A institucionalização do sistema do mérito como meio indispensável ao preenchimento ordinário dos cargos públicos, através do qual se procura buscar entre muitos cidadãos exatamente os mais eficientes, é procedimento salutar que propicia maior rapidez na solução dos problemas do desenvolvimento nacional.

Quando se leva em consideração, por exemplo, as coordenadas responsáveis pelo crescimento e a transformação das nossas condições de vida, sobretudo pelo aumento das taxas do Produto Interno Bruto, que se mantém na ordem de $9 \%$ ao ano; indicadores que revelam uma expansão industrial acima de $10 \%$ (dez por cento), coadjuvado com um significativo incremento à expor- 
tação de produtos manufaturados, não se pode embasar uma po. lítica de administração de pessoal com a utilização de métodos apriorísticos.

Ainda mais : o fortalecimento do sistema do mérito favorece o estabelecimento de critérios tendentes à profissionaliza. ção. E tal requisito é indiscutivelmente necessário. O ritmo de desenvolvimento brasileiro que os dados demonstram é realment€ animador. No período de 1964/1970, a renda global (PIB ultrapassou os $50 \%$ (cinquenta por cento); houve uma expansão de $69 \%$ (sessenta e nove por cento) na produção industrial, e as exportações foram duplicadas. A rede nacional de rodovias pavimentadas foi redobrada e no plano educacional as matrículas sofreram um aumento de $140 \%$ (cento e quarenta por cento). ${ }^{4}$

Dessa forma, os grandes objetivos nacionais culminarão na ampla disseminação dos resultados do progresso econômico, alcançando todas as classes de rendas e todas as regiões.

A par desses grandes objetivos, se alinha uma política de pessoal cientificamente administrada que, tendo como um dos princípios fundamentais o fortalecimento do sistema do mérito, alcançará o aperfeiçoamento e a profissionalização do servidor público. Por isso, é oportuno enfatizar que não há mais lugar para as improvisações e a lição de RIGGS parece estar sendo acatada :

"A escolha dos meios, portanto, deixa de ser objeto de um julgamento de valor a favor ou contra esse ou aquele grupo, esse ou aquele funcionário, esse ou aquele método, porque neste particular todas as escolhas são neutras: devem ser determinadas tecnicamente, a fim de procurar-se o máximo de "eficiência" na persecução dos objetivos propostos". 5

Com tais propósitos perseguidos, o que atualmente assistimos, o Governo anda no caminho certo e atingirá os seus objetivos em bases nacionais da estrutura e do funcionamento da administração pública tendo como esteio a prática obrigatória do sistema do mérito. ${ }^{6}$

\section{DETERMINANTES DOS FATORES DE EFICIENCIA}

A vista do enfoque anterior, quando se procurou mostrar a necessidade de institucionalizar o fortalecimento do sistema do mérito, algumas considerações se fazem necessárias sobre os 
meios utilizados para determinar quais os fatores mais importantes que influirão na demonstração da eficiência.

$\mathrm{Na}$ área da política de Pessoal, como se observa nas diretrizes traçadas pelo I Plano Nacional de Desenvolvimento (PND), foram traçados vários princípios que irão motivar a valorização do servidor público e a criação de funcionalismo eficiente. Tais princípios recomendam:

"Gradual execução dos projetos constantes da programação global aprovada, objetivando a reformulação dos planos de classificação e retribuição de cargos e empregos do Serviço Público Civil na esfera federal (Lei n. ${ }^{\circ}$ 5.645/70); treinamento do pessoal incumbido da execução das atividades técnicas; relacionamento, para os grupos de categorias funcionais, dos cargos que devem integrá-los; definição precisa de cada grupo e a estruturação das respectivas escalas de níveis; elaboração do plano de retribuição; estabelecimento de critérios para a constituição dos novos Quadros; elaboração dos regulamentos relativos a provimento, ascensão e progressão funcionais."

Ora, para que se busque objetivos dessa envergadura, é indispensável a fixação de alguns critérios que delimitarão a eficiência. Neste sentido, procurou-se somar os elencos das atribuições cientificamente mensuradas com fatores básicos que forem susCetíveis de indicar níveis salariais razoáveis para o funcionalismo. Assim, as diversas atividades humanas foram analisadas pelo universalmente açeito e consagrado método da fatoração.

sider Dentro dessa ótica, a avaliação de tais fatores leva em consideração fundamentalmente a escolaridade ou a formação profisde de, a importância para o desenvolvimento, as condições especiais de trabalho e as peculiaridades de exercício. ${ }^{7}$

Em resumo, podemos afirmar que a atual orientação política do Governo, na verdade, está voltada para um programa de trabalho que representa autêntica revolução. Uma arcaica e desacreditada estrutura está sendo reformada. Reforma, aliás, significa essencialmente, mudança. Mudança de mentalidade e de métodos de ação administrativa.

fissio A institucionalização do sistema do mérito, calcado na proque ra os brasileiros alcancem os grandes objetivos nacionais. E paa tal, diversas as providências complementares que devem ser 
tomadas : treinamento e aperfeiçoamento dos servidores são medidas indispensáveis, pois os servidores não devem ser abando. nados nas suas unidades de trabalho. Eles precisam ser treinados e aperfeiçoados, pois BECKMANN ensina que "treinar emprega. dos custa dinheiro, mas não treinar custa muito mais" ${ }^{8}$

Mas o que assistimos, com grande satisfação, é uma permanente preocupação dos dirigentes da administração central do pessoal em fortalecer o sistema do mérito, como um dos mais eficientes instrumentos que levará a Administração Pública Brasileira a alcançar as suas finalidades fundamentais.

\section{REFERENCIAS BIBLIOGRAFICAS}

1 - Art. 94, do Decreto-Lei n. 200.

2 - Le Bon, Gustave - "A Psicologia das Multidões" - Ed. Biblioteca de Educação Nacional - Lisboa 1915, pág. 119.

3 - Cavalcanti, Themístocles Brandão - "Instituições de Direito Adminlstrativo Brasileiro"", 2." Ediçãa - Vol. I, pág. 160. 4 - I Plano Nacional de Desenvolvimento Econômico e Social - 1972/74 -
pág. 4. Edição Gráfica IBGE.

5 - RIGGS, F. W. - "A Ecologia da Administração Pública" Traduçẳo Brasileira - Fundação Getúlio Vargas, 1964.

6 - SZAJUFERBER, Salli e Correia Lima, Vicente Ferrer "Administração : Generalidades e seus Instrumentos" DASP-CENDOC-1971 pág. 33.

7 - Exposição de Motivos n. 894 do DASP - de 06.10.72 - pág. 8.934 .

8 - R. O. Beckmann - "How to Train Supervisors" Apud - A. Fonseca Plmentel - "Alguns Aspectos do Treinamento" - Fundação Getúlio Vargas - Rio - 2." Edição - 1966, pág. 18 citado por José Medeiros, in Revista do Serviço Público. Vol. $108-$ n. ${ }^{3}$, pág. 204. 